\title{
Interactive comment on "The significance of coastal bathymetry representation for modelling the tidal response to mean sea level rise in the German Bight” by Caroline Rasquin et al.
}

Philip Woodworth (Editor)

plw@noc.ac.uk

Received and published: 22 September 2019

Separate editorial comments on 'The significance of coastal bathymetry representation for modelling the tidal response to mean sea level rise in the German Bight' by Rasquin et al.

I decided to post these comments now so that the authors can consider them alongside the comments of R1-R3 without further delay. I note that the authors have not responded already to the reviewers' comments.

It is clear from $\mathrm{R} 2$ in particular, and maybe $\mathrm{R} 1$, that there are both several major and 
many minor improvements needed to the paper, although they should be quite feasible to do. So the authors are encouraged to make a new version which, because of the OSD likely changes, I might pass by the reviewers again.

My own general impression is that I found the text not to have been written as well as it should. It is perfectly understandable but it would have been best to have passed it by a native English speaker before submitting the paper. Therefore, I do not understand the comments of a couple of the reviewers that is was 'well written'. I have scribbled many comments on a paper copy of the draft and sent a pdf separately to the lead author (caroline.rasquin@baw.de).

Some particular comments are:

p1, line 8 (and other places) - is the German Bight really in the SE of the North Sea rather than the east.

figures 1 and 2. These have several errors. Fig 1 has degrees longitude and latitude swapped. But anyway they should read North Latitude (deg) and East Longitude (deg).

In figure 1 deep water bathymetry, shown by dark blue, is a negative number whereas in Figure 2 it is a positive number. In Figure 2 it is hard to read the black names.

Explain somewhere that NHN is the German datum which is a good approximation of MSL.

Table 1. replace commas in the numbers with dots which is more normal internationally.

Figure 3. define MEZ in terms of UT

It is not necessary to have 00:00 in the times.

Figure 3. Why is there a slightly different set of 7 stations used for the 2 models (because of the grids presumably). explain better. It is not easy to spot the grouping of blue $A, B$ etc. when printed - I had to blow up the pdf to see that. Anyway Target-Diagram would be better as 'Target Diagram' and things would be clearer if the maximum radius 
was 0.6.

p8, 5 and elsewhere - oscillation volume sounds odd to me although I am struggling to think of something else. perhaps have this sentence read: Therefore, the only difference between models concerns the volume of water exchanged through the tidal cycle, which we call the oscillation volume.

Figure 5. why does this have a different colour scale to Figure 2? It covers almost the same area.

section 2.5 header. Please do not be so cryptic. Perhaps Analysis of Model Simulations. section 3 Model results

p10, 26 - this is not surprising as the volume of water in the estuaries is small.

Figure 6 and others. What is the second b/w scale for? Is that because of the wet/dry areas or what? Anyway it is not explained in the captions. It seems to me it could be just left off.

The paper does not discuss changes in phase lags, only amplitudes. Nothing to say about them?

p15 current velocity should be current speed (velocity is a vector)

Figure 11 and 12 (a) remove the white arrow. You can't have a negative speed.

Somewhere I noted R2 pointing to the recent Schindelegger et al. (2018) paper regarding model validation, and I was reminded of the Harker et al. (2019) paper in Ocean Science concerning the important aspect of whether model tides are allowed to change on an open boundary when MSL changes, and that should be made clear in the present paper.

Interactive comment on Ocean Sci. Discuss., https://doi.org/10.5194/os-2019-84, 2019.
OSD

Interactive

comment
Printer-friendly version

Discussion paper 